\title{
Las im(posibilidades) de lo fantástico y de la "inquietante extrañeza" en la narrativa vanguardista de Felisberto Hernández y de Juan Emar
}

\author{
The (im)possibilities of the fantastic and \\ "the uncanny" in the vanguardist narrative \\ of Juan Emar and Felisberto Hernández
}

\section{Cecilia Rubio}

Universidad de Concepción. Concepción, Chile

crubio@udec.cl

\section{RESUMEN}

En este artículo cuestionaré que las obras de Felisberto Hernández y de Juan Emar se inscriban en lo fantástico, como ha sostenido la crítica. Para ello, revisaré la aplicación a la obra de Hernández del concepto de "lo ominoso" o "la inquietante extrañeza" propuesto por Sigmund Freud en su "Das Unheimliche" (1919). A partir de una lectura atenta de este escrito, demostraré, primero, que las razones para cuestionar esta aplicación se encuentran en este mismo escrito y, segundo, que son también las razones que refutarían la aplicación del concepto freudiano a la obra de Juan Emar. Propondré, finalmente, que ambas obras deben leerse en el marco de las poéticas de la vanguardia histórica.

Palabras clave: Ominoso, vanguardia, poética, uruguayo, Freud, angustia.

\section{ABSTRACT}

In this article I will question the idea that the works by Felisberto Hernández and Juan Emar fall within the context of the fantastic, as the critic has held. For this 
reason, I will examine the use of the concept of "the ominous" or "the uncanny", developed by Sigmund Freud in Das Unheimliche (1919). After an attentive reading of that essay, I will show, first of all, that the reasons for questioning this use can be understood from the text itself and, secondly, that they are also the reasons that would disprove the use of the Freudian concept in Juan Emar's works. Finally, I will put forward that both works should be read within the framework of the poetics of the historical vanguardism.

Keywords: Ominous (the uncanny), vanguardism, poetic, Uruguayan, Freud, anxiety.

Recibido: 06.11.2011. Aprobado: 24.11.2011.

$\square \mathrm{n}$ este artículo cuestionaré la adscripción al género fantástico y a la modalidad de "la inquietante extrañeza" (Sigmund Freud, "Das Unheimliche" (1919)) de las obras del escritor uruguayo Felisberto Hernández (1902-1964) y del chileno Juan Emar (1893-1964); propondré, en cambio, que el efecto de extrañeza en estas obras encuentra su lectura más acabada de acuerdo a las poéticas de la vanguardia.

La obra de Emar constituye una práctica estrictamente vanguardista, puesto que se desarrolló de manera consciente en el marco de las poéticas elaboradas por la vanguardia histórica ${ }^{1}$. En efecto, si descontamos la novela póstuma, Umbral, la totalidad de esta obra se desarrolla en el período de vanguardia, abarcando tres años, desde 1935 -cuando se publica Ayer, Un año y Miltín 1934- a 1937 -cuando se publica Diez. Centraré mi atención en este último texto.

En el caso de Hernández (o Felisberto), una primera dificultad se produce porque su obra es extensa, ya que abarca desde 1925 a 1962, razón por la cual sus críticos suelen dividirla en tres etapas (Fraga de León, 2003) ${ }^{2}$, de las cuales la primera, de 1925 a 1931, que comprende la obra que se conoce como "Primeras invenciones", corresponde a la época de la vanguardia.

${ }^{1}$ Sitúo la vanguardia histórica latinoamericana siguiendo a Jorge Schwartz (1991), quien la inicia en 1914 con el primer manifiesto de Vicente Huidobro, "Non Serviam", y la termina en 1938 con el encuentro en México de Breton, Trotsky y Diego Rivera, que da origen al "Manifiesto por un arte revolucionario independiente".

${ }^{2}$ La segunda etapa abarca la obra del "periodo memorialista", que va de 1942 a 1944, y que comprende tres nouvelles: Por los tiempos de Clemente Colling (1942), El caballo perdido (1943) y Tierras de la memoria (escrita en 1944). La última etapa comprende la obra que se publica entre 1947 y 1962, es decir, el libro de relatos Nadie encendía las lámparas (1947), los relatos largos "La casa inundada" (1949), "Las hortensias" (1962) y Diario del sinvergüenza. Esta es la etapa que se ha relacionado más directamente con la práctica de lo fantástico-onírico. Ver Hernández, 1983. 
La segunda dificultad es que el desconocimiento de la vanguardia uruguaya se ha mantenido durante bastante tiempo, de manera que mientras algunos estudiosos consideran a Hernández el único vanguardista de su país, otros dan a esta vanguardia el mismo estatus que a la del resto del continente. Rosario Ferré (1986) pertenece al primer grupo, pues sigue a Carlos Martínez Moreno, a quien cita cuando dice que Hernández constituyó "una vanguardia sin retaguardia, una exploración a título y riesgo totalmente personales, y en ello radica su originalidad" (17). Según da a entender Ferré, la constancia de la tradición realista fue más fuerte en Uruguay que en otros países, pues, aunque hubo intentos de incorporarse al movimiento internacional de las vanguardias, éstos no lograron penetrar la cultura artística uruguaya de una manera decisiva. Para Ferré, la debilidad y la resonancia escasa de estas iniciativas se prueba al constatar la poca difusión que tuvieron las revistas experimentales de la época, como es el caso de La Pluma, La cruz del sur y Teseo ${ }^{3}$.

Similar postura tiene Hugo Verani (1990), quien sitúa la vanguardia hispanoamericana entre 1916 y 1935, y, siguiendo la misma fuente que Ferré, se refiere a un "apagado vanguardismo uruguayo" (51). Para Verani, Hernández ocupa un lugar clave en la vanguardia de su país, pues es "el primer narrador uruguayo en interiorizar el proceso narrativo, en cultivar una narrativa concebida como empresa imaginaria” (52).

Sin embargo, los estudiosos Klaus Müller-Bergh y Gilberto Mendonça Teles (2009) dedican varias páginas de su estudio antológico a explicar la vanguardia en Uruguay, así como a antologar documentos, todo lo cual permite situar la vanguardia uruguaya como un movimiento acorde con los del resto del continente. Estos autores también dedican palabras a Hernández que lo ubican en la perspectiva de la vanguardia, pues ven en su obra elementos surrealistas y oníricos (311). Además, se refieren a "Explicación falsa de mis cuentos", que ellos leen como un ensayo donde Hernández ofrece un contraste notable con los textos programáticos sobre el cuento de su compatriota Horacio Quiroga, y señalan que Hernández y Ferreiro son los escritores que introducen en la literatura de vanguardia de Uruguay el absurdo, el humor y la fantasía, y, en general, lo que está fuera de una "concepción racional de la vida" (311).

3 Nelson Osorio (1988) señala que La Pluma (Montevideo, 1927-1931) no fue propiamente una revista que se haya identificado con la vanguardia, pero que contribuyó a la difusión del movimiento. Junto a un documento de esta revista, Osorio publica un par de documentos más de la vanguardia uruguaya. 
Por mi parte, concuerdo con todos estos estudiosos en su consideración de la práctica escritural de Hernández como vanguardista, especialmente la que coincide temporalmente con la vanguardia histórica, sea en lo local, sea en lo internacional. Me refiero a "Primeras invenciones", que comprende los libros: Fulano de tal (1925), Libro sin tapas (1929), La cara de Ana (1930) y La envenenada (1931) (Ver Hernández, 1983). No obstante, considero también que la obra felisberteana, iniciada y moldeada en esta época, asume en su conjunto los rasgos característicos de las poéticas vanguardistas.

\section{LA LECTURA DE LO FANTÁSTICO OMINOSO EN FELISBERTO HERNÁNDEZ}

Respecto de la relación de Hernández con lo fantástico, Ferré (1986) cuestiona la supuesta tradición de lo fantástico en Uruguay, señalando que después de Quiroga no hubo más desarrollo del género en el país hasta llegar a Hernández, quien no entronca con la línea "fantástico-realista" de Quiroga, pues está más cerca de la sensibilidad de los argentinos Macedonio Fernández, Borges, Bioy Casares y Cortázar, que practican el cuento "fantásticosubjetivo", el que "dejaría enriquecer sus técnicas por el ultraísmo, el creacionismo y el surrealismo" (1986: 16), y del cual Hernández habría sido un precursor.

Me detendré ahora en la lectura de "la inquietante extrañeza". En su ensayo "Das Unheimliche" de 1919 (Freud, 1992), Freud explica el concepto del mismo nombre, el que ha sido traducido como "lo ominoso", "lo siniestro", o, directamente del francés, "la inquietante extrañeza" ("linquiétante étrangetê"). Pierre Verdevoye (1980) se apoya en este concepto para abordar el lugar clave que la obra de Hernández ocupa en la trayectoria de la literatura fantástica del Río de la Plata:

Con este escritor uruguayo cambia por completo el rumbo de la literatura fantástica. (...) Ya no se habla de fantasmas, demonios, apariciones del más allá, animales extraños, ni hay referencia al espiritismo, a la ciencia, a las creencias misteriosas. La angustia no necesita del ropaje ornamental tradicional para expresarse. Casi se suprimen los símbolos para llegar a la expresión directa, depurada, casi espontánea, de un malestar existencial. Y entonces lo fantástico es verdaderamente esta inquietante extrañeza producida en el lector por la evocación del ambiente en el que el misterio 
no proviene de las cosas, sino de la visión personal del narrador, quien al describir esta visión sin explicarla nos sumerge en el misterio de su otredad, del mecanismo de su imaginación (Verdevoye, 1980: 293).

Con estas palabras, Verdevoye nos da suficientes antecedentes si no para comprender con exactitud el concepto freudiano, al menos para acercarnos a lo que él entiende por tal. En principio, me interesa poner de relieve dos aspectos. Uno es que la afirmación de que en lo ominoso el punto de vista del narrador adquiere preponderancia, efectivamente es sostenida por Freud, pero no de manera central, pues no es explicada sistemáticamente como sí ocurre con otras al parecer más definitorias del concepto. El segundo asunto es la relación directa que Verdevoye establece entre la inquietante extrañeza y el misterio. Si bien este estudioso no se detiene a analizar la obra de Hernández de acuerdo a su propuesta, me parece evidente que estos aspectos son más característicos de dicha obra que de lo ominoso. En el caso del "misterio", ésta es (junto a "lo desconocido") la palabra felisberteana por excelencia para nombrar la zona que necesita ser cubierta por el lenguaje.

Siguiendo explícitamente a Verdevoye, Hugo Verani (1987) aplica el concepto de "la inquietante extrañeza" a El caballo perdido de Hernández, texto de 1943, con el fin de defender la calificación de "fantástica" de la obra felisberteana en su totalidad ${ }^{4}$. Verani intenta explorar lo fantástico en tanto "punto de convergencia de visiones subconscientes" (1987: 133), para lo cual la propuesta de Freud le parece particularmente sugerente.

Aunque Verani recupera aspectos fundamentales del texto freudiano, como la relación entre la reaparición de algo extraño y familiar a la vez, y lo reprimido, así como lo indispensable de la verosimilitud, también entiende la inquietante extrañeza de acuerdo a ideas que en el texto freudiano no parecen centrales, como la de que ésta "se produce cuando se borran las diferencias entre lo imaginario y lo real" (134). De la misma manera, cita a Verdevoye para afirmar la importancia de "la visión personal del narrador" (134). Como se verá en mi lectura, que se interesa en la obra vanguardista, la visión del narrador es igualmente importante, porque es ella la que permite alejar esta obra de "la inquietante extrañeza".

\footnotetext{
${ }^{4}$ Verani discute así la periodización en tres etapas de la obra de Hernández y propone otra de dos etapas, donde la primera corresponde a la vanguardista, "su prehistoria literaria" (1987: 129), y la segunda a dos vertientes que confluyen dentro de la "madurez literaria" de Hernández, a partir de los años cuarenta, la llamada "memorialista" y la llamada "fantástica".
} 


\section{EL CONCEPTO FREUDIANO. ALGUNAS PRECISIONES}

Definiré lo ominoso como la reanimación, debido a un estímulo exterior, de complejos infantiles que habían sido reprimidos o de creencias irracionales que habían sido superadas, y cuyo efecto anímico es un sentimiento de angustia. Me ajusto a los significados con los que trabaja Freud: Das Unheimliche sería algo familiar que habiendo sido sometido a un proceso de desfamiliarización, vuelve a hacerse presente, provocando una angustia particular, que intenta aprehender y que ejemplifica con el relato "El hombre de la arena" (1817) de E. T. A. Hoffmann.

Como se observa, Freud distingue dos fuentes de lo ominoso: los complejos infantiles, por un lado, y las creencias irracionales arraigadas, por otro. Pero Freud realiza una segunda distinción, la que diferencia lo ominoso en la vivencia de lo ominoso producido por el arte literario. Lo que a mí me interesa poner en discusión es el hecho de que pese a que el concepto freudiano pueda resultar apropiado para alguna de las obras de Hernández, particularmente para aquellas en que el punto de vista narrativo es el de un niño o de un adulto que recuerda su infancia, no debe olvidarse esta segunda distinción, según la cual la literatura y la vivencia no producen lo ominoso de la misma manera, ya que para que se produzca lo ominoso literario se requiere una condición, lo que explica por qué la presencia de motivos adscritos a lo ominoso no basta por sí sola para lograr una literatura de este tipo. En efecto, aparte de los motivos que pueden considerarse más cercanos a lo ominoso, como la angustia de castración, que se expresa a través de miembros cortados o separados (especialmente los ojos), la repetición de lo semejante y el retorno involuntario al mismo lugar, los otros motivos son prácticamente los mismos que suelen presentarse en la literatura fantástica decimonónica: el doble, el animismo, la omnipotencia del pensamiento (el cumplimiento de lo deseado o dicho), la magia, el retorno de los muertos y la catalepsia, entre otros, es decir que lo ominoso no excluye lo extranatural.

La condición a la que me refiero afecta, en rigor, tanto a lo ominoso vivenciado como a lo ominoso literario: ambos se presentan en el marco de la vida cotidiana, de allí que si se quiere lograr lo ominoso literario se deba crear una literatura mimética, cuyo referente es la realidad, con todo lo que tiene de conocida. Freud es muy claro en señalar que los relatos maravillosos, que suelen hacer uso de los mismos motivos que una literatura de lo ominoso, no producen en ningún caso este sentimiento angustioso, debido a que las reglas del género se enmarcan dentro de lo antimimético, donde todo puede suceder, sin entrar en conflicto con la realidad cotidiana, y don- 
de tanto los personajes como el lector aceptan este mundo sin sorpresa.

En estricto sentido, Freud distingue tres tipos de mímesis que están imposibilitadas de producir lo ominoso. El cuento maravilloso es el primero de ellos. El segundo corresponde a una literatura que siendo menos "fantástica" que la de lo maravilloso, se distancia del mundo cotidiano por la aceptación de la existencia de seres espirituales superiores, que pueden ser representantes de los muertos o seres de orden demoníaco. En tal caso -dice Freud- "todo lo ominoso que habría adherido a estas figuras se disipa, en tanto constituyen las premisas de esta realidad poética” (1992: 249). El tercer y último tipo se refiere a una literatura que en apariencia se sitúa en la realidad cotidiana, pero exacerbando las posibilidades de lo ominoso, de manera que engaña al lector, que creía estar sumido en la imitación del mundo y, en cambio, se ve enfrentado al retorno de lo superado, que se revela entonces como creencia irracional arraigada, es decir, como superstición. Una variante de este último tipo de mímesis es la que "consiste en ocultarnos largo tiempo las premisas que en verdad [el autor] ha escogido para el mundo supuesto por él, o en ir dejando para el final, con habilidad y astucia, ese esclarecimiento decisivo" (249).

Como se verá luego, este aspecto del tipo de mímesis, formulado con tanto cuidado por Freud, resulta ser uno de los más relevantes para estudiar lo fantástico-ominoso en una obra determinada. Es decir que, y como se desprende de todo lo dicho hasta aquí, la categoría de lo ominoso no se diferencia de otras categorías de lo fantástico por el requerimiento de mímesis realista ni por la presencia/ausencia de hechos extranaturales.

\section{LA (INQUIETANTE) EXTRAÑEZA EN LOS RELATOS DE FELISBERTO HERNÁNDEZ}

Si se trabaja en los estrictos términos del planteamiento de Freud, hay que reconocer que la obra de Hernández, al estar marcada por el espíritu de la narración vanguardista, sobrepasa los límites de lo ominoso. Pero en una mirada más general, puede admitirse que esta obra se inscribiría en la última variante que señala Freud, es decir, en la de una mímesis irrealista que se presenta aparentemente como realista, ya que si bien la mayoría de los relatos felisberteanos transcurre en un mundo cotidiano, las características de este mundo van gradualmente dejándose ver como disímiles o heterogéneas con respecto a la más o menos unívoca realidad que vivimos todos los días.

Como en la obra emariana, más que a un mundo se asiste a la conciencia 
que lo informa, la del personaje, quien al ponerse en escena como sujeto problemático nos abre el amplio espectro de su fantasía, y puesto que se nos ocultan las premisas que la rigen, esta conciencia se vuelve difícil de reconocer, con lo que se niega la identificación realista. Es sobre todo la configuración de la conciencia y de su discurso lo que convierte al personaje en un sujeto, despersonalizado, descentrado, un sujeto vanguardista (Rubio, 2010). Veamos el comienzo de "Historia de un cigarrillo" (de Libro sin tapas), donde el personaje se autopercibe como un sujeto de actuar automatizado: "Una noche saqué una cajilla de cigarrillos del bolsillo. Todo esto lo hacía casi sin querer. No me daba mucha cuenta que los cigarrillos eran los cigarrillos y que iba a fumar" (Hernández, 1983, I: 36, 37). Y el de "La cara de Ana" (del libro homónimo), cuyo narrador nos da a conocer constantemente su especial capacidad y manera de "sentir" el destino: "Además de sentir todas las cosas y el destino parecido a las demás personas, también lo sentí de una manera muy distinta" (52).

Por el contrario, los relatos posteriores del mismo autor que pueden considerarse fantásticos en un sentido tradicional, es decir, aquellos en los que ocurren hechos inexplicables para la razón y para el curso normal de la vida, hechos que no cabe más que catalogar de extranaturales, como la luz que sale de los ojos del protagonista de "El acomodador" (de Nadie encendía las lámparas), son relatos en los que más claramente se perfila un mundo cotidiano equiparable al mundo real, por lo que cumplen con una de las exigencias del género, la de presentar un correlato, un trasfondo contrastivo de "normalidad", para alojar allí problemáticamente los hechos extranaturales. Veamos el comienzo del relato mencionado: "Apenas había dejado la adolescencia me fui a vivir a una ciudad grande. Su centro -donde todo el mundo se movía apurado entre casas muy altas- quedaba cerca de un río" (Hernández, 1983, II: 75). En el párrafo que sigue a éste, el segundo del relato, el narrador autodiegético nos da la siguiente información: "Yo era acomodador de un teatro" (75).

Si se observa bien, Hernández parece tener muy claras las reglas del género fantástico, ya que para construir un relato de este tipo crea un ambiente cotidiano reconocible e informa al lector sobre las coordenadas espaciotemporales de la historia, cuestión en la que no abunda en los otros dos relatos que he citado y que corresponden a la obra temprana.

Como se desprende claramente del texto de Freud, para analizar lo ominoso en un relato se debe trabajar con un texto en que la mímesis sea realista y se produzca en el personaje y en el lector un sentimiento claro de angustia. Veremos el caso de "El vapor" (de La cara de Ana), porque éste comienza 
situando la acción en un escenario realista del cual se nos dan coordenadas reconocibles: "Fui a otra ciudad que tenía un río como para llegar o salir de ella en vapor" (1983, I: 65). Pero a continuación se nos empieza a adentrar en la conciencia algo tortuosa del narrador. Lo interesante, para mí, es la integración de varios elementos que junto con ir configurando esta conciencia como una conciencia particular, algo disociada y despersonalizada, van configurando también el sentimiento de angustia, vinculado como en varios otros relatos del mismo autor, y de Emar, al tópico de la vida como espectáculo y como hecho estético: ya en el muelle donde espera el vapor para dejar la ciudad, recuerda "los momentos de actor que había representado en esa ciudad" (65), y llega a creer que podría ser él mismo "el poema de lo absurdo" (65).

El sentimiento de angustia aparece con varias delimitaciones. Primero, al sentir en el muelle que nadie lo conoce, le sobreviene una "angustia parecida a la de los niños mimados cuando han vuelto de pasear y les sacan el traje nuevo" (65); a esta le sigue una angustia que al mismo personaje se le presenta como de "una crueldad ridícula" (65), y, posteriormente, vuelve a sentir esta misma angustia con un nuevo símil: "La sentí como si dos avechuchos se me hubieran parado uno en cada hombro y se me hubieran encariñado" (65). Una tercera calificación que recibe la angustia es la de "monótona", la que nos es presentada a través de un tercer símil, pues la monotonía es algo como algunos cantos judíos que "parece que nunca encuentran la tonalidad definida (...) y que para ellos es normal no encontrarla" (66).

La conciencia a cuya puesta en escena asistimos de pronto tiene la sensación de un mundo paralelo al mundo real, una especie de figura imitativa en la que el personaje prefiere vivir. El relato finaliza sin que suceda nada en el plano de los hechos, como suele ocurrir también en la narrativa emariana $\mathrm{y}$ en varios de los relatos felisberteanos.

Respecto de la angustia del personaje, hay que fijarse en dos cosas. Por un lado, aunque se expresa a través de un símil de una conducta infantil, la vivencia misma de lo ominoso no alcanza a ser aludida por el símil, porque, en efecto, ¿qué tienen en común la vivencia del personaje en el muelle al dejar la ciudad y la situación del niño que al regresar a casa después de un paseo debe quitarse el traje? Al menos, el sentido no es aprehensible de manera inmediata. Por otro lado, es habitual en los relatos felisberteanos que la angustia devenga en risa, como si fueran dos movimientos anímicos convergentes, y "El vapor" no es una excepción, pues a continuación del símil mencionado el personaje dice: "Me reí de esta ridiculez y traté de reaccionar, pero entonces caí en otra angustia mucho más vieja, más cruel y que 
por primera vez vi que era de una crueldad ridícula” (65). Al sopesar así su angustia, el personaje se distancia de ella, ya que la sensación de ridículo ha sustituido dos veces el sentimiento de angustia. Los símiles, por supuesto, permiten fijar de manera más eficiente el sentimiento, pero no por ello dejan de contribuir al distanciamiento anímico. Y esta es otra de las formas en que los relatos felisberteanos se apartan de lo ominoso.

\section{LA (INQUIETANTE) EXTRAÑEZA EN LOS RELATOS DE JUAN EMAR}

Hay un par de relatos de Diez que resultan significativos de examinar desde la perspectiva freudiana. Me refiero a "El hotel Mac Quice" y "Papusa", pues en ambos se está muy cerca de tematizar de manera explícita algunos de los motivos de lo ominoso señalados por Freud.

En el caso de "El hotel Mac Quice", lo que se produce es lo que Freud llama "el retorno involuntario al mismo lugar", forma específica de "la repetición de lo igual" (1992: 237), que, a su vez, estaría relacionada con la "compulsión de repetición" de la etapa infantil. Freud ejemplifica estos motivos con relatos de vivencias en que una persona se pierde en una ciudad desconocida -como en el relato emariano-, en un camino con niebla, y en una habitación a oscuras, lo que en todos estos casos culmina con la vuelta reiterada al mismo lugar o el choque con el mismo obstáculo. En todas estas repeticiones, dice Freud, se impone la idea de lo fatal, de lo inevitable a pesar de uno mismo. Es una sensación que pone en jaque el libre albedrío y afirma la existencia del destino, es decir, se contrasta lo racional con una creencia precientífica o acientífica. Por eso es que Freud señala que si se descubriera una ley para estos casos y los de coincidencias de nombres, números, personas, etc., que a veces ocurren en el mismo día, la impresión de lo ominoso dejaría de presentarse. Pero no la hemos descubierto, y entonces no siempre somos "impermeables a las supersticiones" (1992: 238).

De nuevo me limito a examinar el principio y el final del relato. En cuanto al comienzo, no se parte por situar al lector en un escenario plenamente irrealista, pero tampoco totalmente cotidiano, pues aunque se nos informa que los personajes abandonan el hotel para salir de la ciudad que están visitando, se procede a describir latamente no sólo los pasillos del hotel y el color de cada objeto, sino los movimientos de los personajes al caminar, a lo que le seguirá una larga y caótica lista de objetos olvidados en el hotel, entre los cuales está la hermana del narrador. El final del relato, por su parte, desa- 
fía toda salida racional del problema de estar perdido en la ciudad y regresar siempre a la misma plaza (la que luego se duplica), pues se quiere dar la impresión de que los personajes están imposibilitados de volver a encontrarse, como si vivieran en dimensiones o tiempos paralelos, lo que algunos llaman "la cuarta dimensión" (Cebrián López, 2006). Esto que dicho así puede producirnos una fuerte sensación de pavor, no tiene el mismo efecto sobre el protagonista, o al menos, ese importante contenido de su conciencia no nos es comunicado. Más bien da la impresión de que el personaje se abandona con desdén, resignación o la misma indolencia que le hemos visto en otros relatos emarianos a la circunstancia de estar perdido y aislado para siempre.

Más claro aun en su reminiscencia freudiana es el relato "Papusa". Lo primero que hay que decir respecto del tipo de mímesis es que éste es uno de los pocos relatos emarianos en que nos encontramos desde el inicio con la ocurrencia de un hecho extranatural que sitúa la historia de manera irrealista: "Desde Belcebú, por línea recta, viene rodando, a través de todos mis antepasados, un ópalo. Hace largos años llegó en su rodar a mí, pues todo mi linaje había bajado a la tumba y Belcebú no se presentaba de siglos atrás sobre la tierra" (Emar, 2006: 101).

Este comienzo no sólo no es adecuado para el género de lo fantástico, por el ya señalado hecho de poner en escena una mímesis irrealista que no encontrará medio de contraste en un mundo narrado natural y cotidiano, sino que también corresponde a uno de los tipos de mímesis señalados por Freud que estarían imposibilitados de producir lo ominoso, dado que se funda en la creencia y aceptación de que existen seres espirituales de orden demoníaco, creencia que forma parte de las premisas de la realidad ficticia, con lo cual se desprende de estas figuras todo su contenido ominoso. Como se observa, lo que ocurre en este tipo de relatos es que resulta indiferente tanto si el autor como si el lector comparte con el texto el sistema de creencias en que se funda, pues lo importante es que el mundo narrado se sustenta en él y se constituye como un mundo inviolable desde cualquier racionalidad distinta a la que organiza su contenido y a la que se somete el personaje.

Junto con ello, el mundo de la escena que ocurre dentro del ópalo y que el narrador contempla está asimismo sujeto a premisas como la que sostiene "el espectro" de que "los humanos vinieron sin sexo" (Emar, 2006: 105), pero éste les fue incrustado, de manera que se creó una simbiosis entre el ser humano y el sexo, que perdura hasta hoy. Es imposible reproducir aquí todas las premisas de esta teoría, me limito a resaltar, por lo tanto, que en el relato llega un momento en que parece que se estuviera parafraseando a 
Freud, porque debe tenerse en cuenta que éste considera también entre las posibilidades de lo ominoso la de que se reanimen en la persona creencias irracionales arraigadas que estuvieron vigentes en estadios anteriores de la humanidad, creencias que sobreviven en estado latente y que retornan a la conciencia a través de estímulos que poseen algún grado de analogía con la creencia superada. Veamos lo que dice el espectro a continuación del anuncio de que algunos seres han desprendido de ellos algo como una función sexual que actúa por sí sola: "Recuerda, ahora, en ti mismo un hecho lejano, acaso olvidado, pero cuya esencia ha quedado en ti causándote pavor cada vez que la vida te ha ofrecido algo análogo. Oye bien: ¿puedes negarme que un pavor 'inexplicable' - por la distancia entre causa y efecto- te coge cada vez que sorpresivamente descubres vida en lo que creías inanimado?” (106). Luego de dar dos ejemplos de esta sensación de vida de lo inanimado -lo que, por lo demás, es uno de los primeros ejemplos que menciona Freud- el espectro sentencia: "Pavor que se hunde lejos en tu infancia y que ahora hechos en cierto modo semejantes golpean como un eco" (107). El motivo de lo ominoso según el cual se tuvo en la infancia el deseo de que lo inanimado, por ejemplo, las muñecas, cobrara vida, es revivido aquí como temor, temor ominoso, en el lenguaje de Freud; pavoroso en el de Emar. Este motivo, como en algunos de los ejemplos de Freud, no es "puro", ya que se mezcla o va deviniendo otros, pues la separación en uno del sexo engendra la sensación de dualidad, que es otro de los motivos de lo ominoso.

Dadas estas coincidencias, es bueno recordar también que Freud explica con cierta detención que el complejo infantil de castración se expresa (para el psicoanálisis) en miembros cortados o separados del cuerpo, lo que se liga al temor de que los ojos nos sean arrancados. El ejemplo paradigmático es, sin duda, Edipo Rey, el momento en que, según la ley del Talión, Edipo tendría que haberse castrado y en cambio opta, como en un acto simbólico, por arrancarse los ojos. Esto me interesa porque permite releer o repensar dos motivos que se presentan en "El pájaro verde", dos motivos que en nuestra percepción aparecen como uno solo, el primero, el recobramiento de vida por parte del loro embalsamado, y, segundo, el ataque que este loro revivido emprende sobre el tío José Pedro, cuyo "tercer picotazo" tiene como objeto un ojo, que es descrito con toda minuciosidad, como corresponde al tópico de la vida como espectáculo: "El ojo de mi viejo tío era de una redondez perfecta salvo en el punto opuesto a la pupila donde crecía una como pequeña colita que me recordó inmediatamente los ágiles guarisapos que pueblan los pantanos" (Emar, 2006: 22). En todo caso, y como el lector sabe de sobra, no es el "espectáculo pasmoso" (239) del tío lo que inquieta al personaje, 
puesto que la vida estetizada, paralela, vida en el lenguaje, convierte al personaje en un espectador que contempla desde la indolencia moral.

Como se observa, lo que verdaderamente se presenta en los relatos emarianos $-\mathrm{y}$ en los felisberteanos- es un personaje que ya desde el inicio de la historia narrada se encuentra en conflicto con la realidad natural (es decir, cultural) en que debe vivir. El espectáculo del ataque y de la incapacidad moral del narrador para reaccionar de manera "humana" (Ortega y Gasset, 1932) va tomando toda la atención del lector. ¿Será entonces que Sartre (1947) está en lo correcto cuando señala que lo verdaderamente fantástico en el siglo XX es el ser humano?

En Emar nos encontramos con distintos recursos de distanciamiento que impiden que se forme en los personajes y en los lectores el sentimiento de lo ominoso: en "El hotel Mac Quice" se trata de una resolución de la historia que es imposible de experimentar en nuestra vivencia cotidiana; en "Papusa", de las premisas que sostienen el mundo narrado; en "El unicornio", del desdoblamiento literal del personaje; en "El pájaro verde", de la estetización del hecho ominoso.

Como espero haber demostrado, la vanguardia da estatuto legítimo en la literatura a todo mundo narrado que experimente y juegue con los mundos posibles literarios, con la supremacía de la ficcionalización, con la crisis de la representación realista. Esta poética autonomista del arte, lejos de negar la relación entre la obra literaria y el contexto histórico en el que surge, defiende el carácter autotélico del arte, sobre todo en cuanto al discurso moralista y pedagógico que reinaba en el naturalismo positivista. Junto con ello, la prosa vanguardista hace uso del resorte humorístico, del recurso a lo onírico, de la actitud y enunciados metanarrativos, del dialogismo polémico y paródico (Bajtín, 1986), de la estética deshumanizante (cf. Ortega y Gasset), y, en el caso específico de Emar, de una declarada visión ocultista del mundo. Por todo esto, si lo fantástico o fantasioso se presenta, llega a constituir otra forma de realidad (una forma paralela) que irrumpe atacando y poniendo en jaque la estabilidad (moral, quizás sobre todo) de nuestro mundo.

Ese mundo paralelo forma parte del contenido latente del mundo manifiesto. En este sentido, es cierto que Emar y Hernández se acercan al surrealismo. La aceptación del personaje de este contenido latente es lo que no permite que haya en él sorpresa ni temor, ni cuestionamiento de la veracidad de lo que ha ocurrido. La visión de mundo en los relatos emarianos y felisberteanos corresponde a la visión vanguardista del mundo, la que es llevada al plano diegético, es decir, una visión según la cual la realidad está organizada de acuerdo a una lógica y una racionalidad que hay que vigilar y 
cotejar constantemente. Es el absurdo una verdadera fisura que se deja exhibir en esa cosa aparentemente compacta que llamamos realidad, fisura que se deja invadir o simplemente penetrar por fuerzas heterogéneas y dispersas. El sinsentido de lo que se creía ordenado asalta por todas partes, porque es constituyente de la visión de mundo del narrador.

\section{REFERENCIAS}

Bajtín, M. 1986. Problemas de la poética de Dostoievski. México: Fondo de cultura económica.

Cebrián López, M. 2006. "La noción de cuarta dimensión en artistas latinoamericanos”. En J. M. Martínez (Ed.), Arte americano: contextos y formas de ver. Santiago: Ril editores, pp. 311-317.

Emar, J. 1996a. Un año. Santiago: Editorial Sudamericana. . 1996b. Umbral. 5 Vols. Santiago: DIBAM-Biblioteca Nacional. . 1998. Miltín 1934. Santiago: Dolmen ediciones. 2006. Diez. Santiago: Tajamar ediciones. 2010. Ayer. Buenos Aires: Final abierto.

Ferré, R. 1986. "El acomodador". Una lectura fantástica de Felisberto Hernández. México: Fondo de cultura económica.

Fraga de León, R. 2003. Felisberto Hernández. Proceso de una creación. Lima: Pontificia Universidad Católica del Perú.

Freud, S. 1992. "Lo ominoso". En Obras completas (J. L. Etcheverry, Trad., Vol. 17). Buenos Aires: Amorrortu editores, pp. 215-251.

Hernández, F. 1983. Obras completas. M. L. Puga (Ed.) México: Siglo veintiuno editores.

Müller-Bergh, K. y Gilberto Mendonça Teles. 2009. Vanguardia latinoamericana. Historia, crítica y documentos (Vol. V). Madrid: Vervuert-Iberoamericana.

Ortega y Gasset, J. 1932. "La deshumanización del arte”. En La deshumanización del arte: Ideas sobre la novela. Santiago: Cultura, pp. 3-55.

Osorio, N. 1988. Manifiestos, proclamas y polémicas de la vanguardia literaria hispanoamericana. Caracas: Biblioteca Ayacucho.

Rubio, C. 2010. "Ciudad moderna y trayectos del deseo en la escritura de Juan Emar”. En Diálogos del Bicentenario: Concepción-Alicante. Concepción: Universidad de Concepción, pp. 243-261.

Sartre, J. P. 1947. "Aminadab ou du fantastique considéré comme un langage”. En Situations, I. Paris: Gallimard, pp. 122-142. 
Schwartz, J. 1991. Las vanguardias latinoamericanas: textos programáticos y críticos. Madrid: Cátedra.

Verani, H. 1987. "Felisberto Hernández: la inquietante extrañeza de lo cotidiano", en Anales de literatura hispanoamericana 16, pp. 127-144.

1990. Las vanguardias literarias en Hispanoamérica (Manifiestos, proclamas y otros escritos). México: Fondo de cultura económica.

Verdevoye, P. 1980. "Tradición y trayectoria de la literatura fantástica en el Río de la Plata", en Anales de literatura hispanoamericana 9, pp. 283-303. 